\title{
Prevalence, Presenting Complaints, Risk Factors and Comorbidity of Acute Coronary Syndrome at Orotta National Referral Hospital Intensive Care Unit Eritrea: Retrospective Study
}

\author{
Elias Teages Adgoy ${ }^{1, *}$, Yemane Seyoum ${ }^{2,4, *}$, Abiel Berhe ${ }^{4}$, Yoseph Tewolde ${ }^{3,4}$, Fitsum Kibreab \\ ${ }^{1}$ Department of Community Medicine and Primary Health Care, Orotta School of Medicine and Dentistry, Asmara, Eritrea \\ ${ }^{2}$ Department of Internal Medicine, Orotta School of Medicine and Dentistry, Asmara, Eritrea \\ ${ }^{3}$ Department of Surgery, Orotta School of Medicine and Dentistry, Asmara, Eritrea \\ ${ }^{4}$ Ministry of Health, Orotta National Referral Hospital, Asmara, Eritrea \\ ${ }^{5}$ Ministry of Health, Asmara, Eritrea
}

\section{Email address:}

eliasteages@gmail.com (E. T. Adgoy),ssyemane@yahoo.com (Y. Seyoum), abielberhe7@gmail.com (A. Berhe), yghidei@yahoo.com (Y. Tewolde), fachekg4@gmail.com (F. Kibreab)

${ }^{*}$ Corresponding author

\section{To cite this article:}

Elias Teages Adgoy, Yemane Seyoum, Abiel Berhe, Yoseph Tewolde, Fitsum Kibreab. Prevalence, Presenting Complaints, Risk Factors and Comorbidity of Acute Coronary Syndrome at Orotta National Referral Hospital Intensive Care Unit Eritrea: Retrospective Study. Science Journal of Public Health. Vol. 5, No. 6, 2017, pp. 457-463. doi: 10.11648/j.sjph.20170506.18

Received: October 10, 2017; Accepted: November 7, 2017; Published: November 17, 2017

\begin{abstract}
Coronary Heart Disease (CHD) being one of the major manifestations of atherosclerotic cardiovascular disease, it ranks a third for all deaths above the age of 35 in developed countries. It is the principal cause of mortality globally for greater than 4.5 million people in the developing world with a relative lack of preventive measures implemented. Eighty percent of deaths due to Cardiovascular Diseases (CVD) occur in developing countries. CHD rates are expected to increase in developing countries mainly South East Asia, Sub-Saharan Africa, Latin America, and the Middle East; from 9 million in 1990 to 19 million by 2020. This Retrospective study was carried out to assess the Prevalence, Presenting Complaints, Risk factors and Comorbidity of Acute Coronary Syndrome (ACS) at Orotta National Referral Hospital Intensive Care Unit, Asmara, Eritrea. Hospital based Retrospective record review study of ten years was done on clinical cards of patients. The study results revealed an overall prevalence of 8.5 percent. ACS was observed to increase with an increasing age, being higher in 164 patients (55\%) who are in the age group greater than sixty. Majority $(86.6 \%)$ of admissions were reported as from zoba Maekel. It was observed to increase in males than females with 3.66 to 1 ratio of male to female. Chest pain was documented as a chief complaint $(85.23 \%)$. The average length of hospital stay until discharged or death was found to be 11 days. Comorbidity between Hypertension, Diabetes and ACS was documented as 55.4 percent showing a significant association $(\mathrm{P}$ Value $=0.001)$. The study results also revealed a significant association between sex and, NSTEMI and STEMI at a P- value $=0.003$, but no any association was found among NSTEMI and STEMI, and age, smoking, cholesterol level, Diabetes and Hypertension. In conclusion, this study revealed that ACS is increasing in Eritrea as any other developed and developing countries. The association between sex and, NSTEMI and STEMI which may be attributed to modifiable behavioral risk factors that are gender related. Therefore, the study recommends to Clinicians to ask and record, family history of premature CHD death, duration of Diabetes, Hypertension and other chronic cardio-pulmonary diseases, all diagnostic investigations and specific medications that are used for the management of the disease and good outcome.
\end{abstract}

Keywords: Coronary Heart Disease, Acute Coronary Syndrome, Intensive Care Unit, Presenting Complaints, Risk Factors, Comorbidity 


\section{Introduction}

Coronary Heart Disease (CHD) being one of the major manifestations of atherosclerotic cardiovascular disease, it ranks a third for all deaths above the age of 35 in developed countries [1]. Eighty percent of deaths due to Cardiovascular Diseases (CVD) occur in developing countries and CHD is the principal cause of mortality globally for greater than 4.5 million people in the developing world with a relative lack of preventive measures implemented [2,3]. CHD rates are expected to increase in developing countries (South East Asia, sub-Saharan Africa, Latin America, and the Middle East) from 9 million in 1990 to 19 million by 2020 due to aging, nutritional change, physical inactivity, tobacco and alcohol use $[2,3]$. It was projected to reduce by $24-50$ percent in mortality since 1975 , but still it is the leading cause of death in affluent countries [4]. A study that was done before twenty years indicated that the prevalence of CHD in Africa as rare because of low socioeconomic status [5]. Age-standardized mortality rates due to CHD was predicted to rise by 27 percent and 25 percent in men and women in 2015 and it was projected also to rise by 70 and 74 percent by 2030 in African men and women, respectively. This is probably due to surge of the risk factors such as hypertension, diabetes mellitus, obesity, physical inactivity, increased tobacco smoking and dyslipidaemia. The nutritional, demographic and epidemiologic transitions are causing an increase in the epidemics of noncommunicable disease [6].

A systematic review that was done by Hertze et al. (2014), on seven observational studies that included 92,378 participants from 5 countries (South Africa, Sudan, Nigeria, Senegal, and Kenya); indicated that the prevalence of acute myocardial infarction was ranging from 0.1 to 10.4 percent [7]. A study by Yusuf et al. (2004), that included 28000 subjects from 52 countries revealed 90 percent of the attributable risk factors for acute myocardial infarction were hypertension, diabetes, central obesity, dyslipidaemia, physical inactivity, psychological stress, tobacco use, inadequate intake of fruits and vegetables and alcohol intake [8]. Similar study by Steyn et al. (2005), also documented similar attributable risk factors such as dyslipidaemia, abdominal obesity and tobacco use with higher risk in comparison to hypertension and diabetes [9]. A study that was done at Teaching Hospital in Nigeria, by Joseph, for a ten year analysis of cases, documented the most common presenting symptoms of acute coronary syndrome as extreme weakness, sweating, and left ventricular failure and sever chest pain; in addition the study also revealed the prevalence of transmural infarct (Q wave infarct) as 38.5 percent [10]. A five years retrospective study on Myocardial Infarction (MI) by Seyoum \& Leake (2002), from 1997 to 2001, at Halibet National Referral Hospital, Asmara, Eritrea documented the incidence of acute Myocardial Infarction as 4.35 per 1000 admissions. The study results indicated also the average age of patients as 60 years with 5 to 1 , male to female ratio. The study documented the major modifiable and non-modifiable risk factors such as smoking, uncontrolled hypertension, diabetes mellitus. Mortality rate was reported to be 35.8 percent which is concordant with studies that were done in the United States, mainland Europe [11]. According to WHO (2011), in Eritrea the prevalence of cigarette smoking was 6 percent ( $13 \%$ for men and less than $1 \%$ for women); and in 2010 the prevalence of total alcohol per capital consumption, raised blood pressure and obesity were reported to be 1.1 percent, 23.2 percent and 1.5 percent, respectively [12]. There are studies that reported the prevalence of MI which is close prevalence of Coronary Artery Disease (CAD), including ST elevation MI and non ST elevation MI [13].

\section{Materials and Methods}

A ten year hospital based retrospective record review study was done on patients who were admitted to Orotta National Referral Hospital Intensive Care Unit (ONRH-ICU), from 2005 to 2015 for assessing the Prevalence, Presenting Complaints, Risk factors and Comorbidity of Acute Coronary Syndrome (ACS). The patients were selected based on World Health Organization (WHO) criteria, International Classification of Diseases (ICD) -10 Code: I 23 [14]. Data was collected from the In-Patient Medical Department (IPMD) $\log$ book using a structured questionnaire. After data collection the data was entered in to excel sheet, cleaned and then exported to SPSS version 20 for analysis

\section{Results}

\subsection{Prevalence of ACS from 2005 to 2015}

In the 10 years period from 2005 to 2015 , a total of 3503 patients were admitted to Orotta National Referral Hospital Intensive Care Unit (ONRH-ICU). Out of these 298 patients were admitted with the diagnosis of ACS. The admission rates of ACS cases in ONRH- ICU had showed a gradual increase in the last 10 years, from $2005(6 \%)$ to 2015 $(10.5 \%)$ with an average increase of 8.5 percent (Table 1).

Table 1. Total admission and prevalence of ACS.

\begin{tabular}{|c|c|c|c|}
\hline Year of Admission & Patients admitted to ONRH-ICU (N) & Patients admitted to ONRH-ICU (N) & Patients with ACS (\%) \\
\hline 2005 & 265 & 16 & 6.0 \\
\hline 2006 & 354 & 22 & 6.2 \\
\hline 2007 & 253 & 20 & 7.9 \\
\hline 2008 & 353 & 16 & 4.5 \\
\hline 2009 & 283 & 19 & 6.7 \\
\hline 2010 & 326 & 31 & 9.5 \\
\hline 2011 & 299 & 24 & 8.0 \\
\hline
\end{tabular}




\begin{tabular}{llll}
\hline Year of Admission & Patients admitted to ONRH-ICU (N) & Patients admitted to ONRH-ICU (N) & Patients with ACS (\%) \\
\hline 2012 & 306 & 37 & 12.1 \\
2013 & 339 & 35 & 10.3 \\
2014 & 323 & 36 & 11.1 \\
2015 & 402 & 42 & 10.4 \\
Total & 3503 & 298 & 8.5 \\
\hline
\end{tabular}

\subsection{Background Information}

Majority $(92 \%)$ of the patients with ACS were married. The admission flow was higher (86.6\%) from Zoba Maekel. Majority (81.54) of the patients were Christian by religion.
There was no single admission from Debubawi Keih-Bahri Zone but the results showed 1.68 percent $(\mathrm{n}=5)$ of foreigners and from diaspora, of which 1.01 percent $(n=3)$ were Indians (Table 2).

Table 2. Background information of Patients with ACS.

\begin{tabular}{|c|c|c|}
\hline Variable & Frequency (n) & Percent (\%) \\
\hline \multicolumn{3}{|l|}{ Age } \\
\hline $20-29$ & 6 & 2.02 \\
\hline $30-39$ & 29 & 9.76 \\
\hline $40-49$ & 42 & 14.14 \\
\hline $50-59$ & 56 & 18.86 \\
\hline $60-69$ & 74 & 24.92 \\
\hline $70+$ & 90 & 30.30 \\
\hline Missed & 1 & 0.34 \\
\hline Total & 298 & 100 \\
\hline \multicolumn{3}{|l|}{ Sex } \\
\hline Female & 64 & 21.48 \\
\hline Male & 234 & 78.52 \\
\hline Total & 298 & 100 \\
\hline \multicolumn{3}{|l|}{ Zone } \\
\hline Maekel & 258 & 86.58 \\
\hline Debub & 15 & 5.03 \\
\hline Gash Barka & 7 & 2.35 \\
\hline Anseba & 6 & 2.01 \\
\hline Semenawi Keih-Bahri & 7 & 2.35 \\
\hline Foreigners/Diaspora & 5 & 1.68 \\
\hline Total & 298 & 100 \\
\hline \multicolumn{3}{|l|}{ Religion } \\
\hline Christian & 243 & 81.54 \\
\hline Moslem & 50 & 16.78 \\
\hline Hindu & 3 & 1.01 \\
\hline Missed & 2 & 0.67 \\
\hline Total & 298 & 100 \\
\hline \multicolumn{3}{|l|}{ Marital status } \\
\hline Married & 275 & 92.28 \\
\hline Single & 23 & 7.72 \\
\hline Total & 298 & 100 \\
\hline
\end{tabular}

The ten year results showed an increase trend of ACS with increasing age being higher in 164 patients (55\%) who are in in the age group greater than sixty. ACS was observed to increases in males than females with the increase of patients age (Table 3). The male $(\mathrm{n}=234)$ to female $(\mathrm{n}=64)$ ratio was 3.66 to 1 .

Table 3. Age, Sex and Distribution of Patients with ACS.

\begin{tabular}{llll}
\hline Age & Female & Male & Total Number of patients with ACS \\
\hline $20-29$ & 0 & $6(100 \%)$ & 6 \\
$30-39$ & $6(20.69 \%)$ & $23(79.31 \%)$ & 29 \\
$40-49$ & $11(26.19 \%)$ & $31(73.81 \%)$ & 42 \\
$50-59$ & $9(16.07 \%)$ & $47(83.93 \%)$ & 56 \\
$60-69$ & $16(21.62 \%)$ & $58(78.38 \%)$ & 74 \\
$70+$ & $22(24.44 \%)$ & $68(75.56 \%)$ & 90 \\
Missed & 0 & $1(100 \%)$ & 1 \\
Total & $64(21.48 \%)$ & $234(78.52 \%)$ & 298 \\
\hline
\end{tabular}




\subsection{Presenting Complaints, Length of Hospital Stay and Referral}

Majority ( $85.23 \%$ ) of patients presented chest pain as a chief complaint whereas shortness of breath, epigastric pain, palpitation and others were found to be 6 percent, 4 percent 1.3 percent and 3.4 percent, respectively (Table 4 ).

Table 4. Presenting complaints in patients with ACS.

\begin{tabular}{lll}
\hline Variable & Frequency (n) & Percent (\%) \\
\hline Chest Pain & 254 & 85.23 \\
Shortness of Breath (SOB) & 18 & 6.04 \\
Epigastric Pain & 12 & 4.03 \\
Others & 10 & 3.36 \\
Palpitation & 4 & 1.34 \\
\hline
\end{tabular}

Others $*$ include $=$ Generalized body weakness, fall down, loss of consciousness and seizure

The average length of hospital stay until discharged or death was 11 days. Majority (71.5\%) of patients were selfreferrals whereas 28.52 were referred from health facilities (Table 5).

Table 5. Hospital stay and Referral.

\begin{tabular}{lll}
\hline Variables & Frequency (n) & Percent (\%) \\
\hline Average Length of Stay in Days & & \\
$<5$ & 50 & 16.78 \\
$5-9$ & 99 & 33.22 \\
$10-14$ & 74 & 24.83 \\
15 and above & 75 & 25.17 \\
Total & 298 & 100 \\
Referral & & \\
Facility Referral & 85 & 28.52 \\
Self-Referral & 213 & 71.48 \\
Total & 298 & 100 \\
\hline
\end{tabular}

\subsection{Prevalence of Risk Factors and Co-Morbidity}

Table 6. Risk factors in patients with ACS.

\begin{tabular}{lll}
\hline Variable & Frequency (n) & Percent (\%) \\
\hline Smoking & & \\
No & 110 & 36.9 \\
Yes & 54 & 18.1 \\
Missed & 134 & 44.97 \\
Total & 298 & 100 \\
Hypertension & & \\
No & 189 & 63.42 \\
Yes & 109 & 36.58 \\
Total & 298 & 100 \\
Diabetes & & \\
No & 206 & 69.13 \\
Yes & 92 & 30.87 \\
Total & 298 & 100 \\
\hline
\end{tabular}

The prevalence of smoking in patients with Acute Coronary Syndrome (ACS) who were admitted to Orotta National Referral Hospital Intensive Care Unit (ONRH-ICU) from 2005 to 2015 was recorded for 164 out of 298 patients with ACS having 33 percent $(n=54)$ as smokers and 67 percent $(n=112)$ as nonsmokers. In one third of patients with ACS hypertension and diabetes were observed to be as risk factors with a prevalence of 37 and 31 percent (Table 6).

Comorbidity between Hypertension and Diabetes in ACS patients was documented in 55.4 percent $(n=51)$ of the patients which was found to have significant association $(\mathrm{P}$ Value $=0.001)($ Table 7$)$.

Table 7. Comorbidity between Hypertension and Diabetes in patients with ACS.

\begin{tabular}{lllll}
\hline Variable & Diabetic & Non Diabetic & Total & P value \\
\hline Hypertensive & 51 & 58 & 109 & $<0.001$ \\
Non Hypertensive & 41 & 148 & 189 & \\
\hline
\end{tabular}

The study results showed a significant association between sex and, NSTEMI and STEMI at a P-value $=0.003$, whereas there was no any association among NSTEMI and STEMI, and age, smoking, cholesterol level, diabetes and hypertension (Table 8).

Table 8. Risk factors and type of MI.

\begin{tabular}{|c|c|c|c|c|c|c|c|}
\hline \multirow[t]{2}{*}{ Variable } & \multicolumn{2}{|c|}{ NSTEMI } & \multicolumn{2}{|c|}{ STEMI } & \multicolumn{2}{|c|}{ Total } & \multirow[t]{2}{*}{$P$ value } \\
\hline & (n) & $(\%)$ & (n) & $(\%)$ & (n) & $(\%)$ & \\
\hline \multicolumn{8}{|l|}{ Sex } \\
\hline Female & 22 & 34.92 & 42 & 17.87 & 64 & 21.48 & 0.003 \\
\hline Male & 41 & 65.08 & 193 & 82.13 & 234 & 78.52 & \\
\hline Total & 63 & 100 & 235 & 100 & 298 & 100 & \\
\hline \multicolumn{8}{|l|}{ Age } \\
\hline $20-29$ & 2 & 33.33 & 4 & 66.67 & 6 & 100 & \\
\hline $30-39$ & 8 & 27.59 & 21 & 72.41 & 29 & 100 & \\
\hline $40-49$ & 10 & 23.81 & 32 & 76.19 & 42 & 100 & 0.863 \\
\hline $50-59$ & 10 & 17.86 & 46 & 82.14 & 56 & 100 & \\
\hline $60-69$ & 15 & 20.27 & 59 & 79.73 & 74 & 100 & \\
\hline $70+$ & 18 & 20 & 72 & 80 & 90 & 100 & \\
\hline Missed & - & - & - & - & 1 & 0.33 & \\
\hline Total & 63 & 100 & 234 & 100 & 297 & 99.7 & \\
\hline \multicolumn{8}{|l|}{ Smoking } \\
\hline No & 29 & 72.5 & 81 & 65.32 & 110 & 67.07 & 0.401 \\
\hline Yes & 11 & 27.5 & 43 & 34.68 & 54 & 32.93 & \\
\hline Total & 40 & 100 & 124 & 100 & 164 & 100 & \\
\hline \multicolumn{8}{|l|}{ Cholesterol } \\
\hline Borderline high & 6 & 22.2 & 21 & 77.8 & 27 & 100 & \\
\hline Desirable & 30 & 23.8 & 96 & 76.2 & 126 & 100 & 0.969 \\
\hline High & 3 & 21.4 & 11 & 78.6 & 14 & 100 & \\
\hline Total & 39 & & 128 & & 167 & & \\
\hline \multicolumn{8}{|l|}{ Diabetes } \\
\hline No & 46 & 22.3 & 160 & 77.7 & 206 & 100 & 0.45 \\
\hline Yes & 17 & 18.5 & 75 & 81.5 & 92 & 100 & \\
\hline Total & 63 & 21.1 & 235 & 78.9 & 298 & 100 & \\
\hline \multicolumn{8}{|l|}{ Hypertension } \\
\hline No & 39 & 20.6 & 150 & 79.4 & 189 & 100 & 0.779 \\
\hline Yes & 24 & 22 & 85 & 78 & 109 & 100 & \\
\hline Total & 63 & 21.1 & 235 & 78.9 & 298 & 100 & \\
\hline
\end{tabular}

\section{Discussion}

Acute Coronary Syndrome (ACS) is increasing in Eritrea as many other developed and low -income developing countries mainly that include the Sub-Saharan African (SSA) countries. A gradual increase in the prevalence of Acute Coronary Syndrome was observed in the years from 2005 to 2015. The prevalence was observed to increase 6 percent 
10.5 percent with an average increase of 8.5 percent. A four year retrospective study on clinical records of ICU patients that was done in 2002 at Halibet Regional Referral Hospital Intensive Care Unit (HRRH-ICU), Asmara, Eritrea recorded an admission rate of 4.7 percent of the total admission to the respective ICU [11]. This increase is resulted due to an epidemiological shift from communicable to noncommunicable diseases which is mainly related to life style and nutritional change in the developed and developing countries. A prospective study that was conducted in Kenya, in the year 2008 - 2010 documented a prevalence of 5 percent [15]. Another systematic review study on acute myocardial infarction in five Sub-Saharan African (SSA) countries (2014), also noted a range of 0.1 to 10.4 percent which is similar with the above mentioned results [7].

A review conducted by Okrainec, Banerjee \& Eisenberg (2004), concerning Coronary Artery Disease (CAD) for the years 1990 to 2002 in developing countries had showed an increase in prevalence being in the top of causes of death that could give a projection for doubling from 1990 to 2020 with an estimated increase of 82 percent in the developing countries which is attributed to rapid socioeconomic growth that leads to aggregated exposure to the risk factors, that include mainly diabetes, hypertension, and smoking [2]. In Eritrea as other developing countries the prevalence of Diabetes increased from (2.3\%) in 2004 to (4.7\%) 2010 [16, 17]. So this has congruence with the above studies that have been indicated in relation to the risk factors. As it is indicated in the study results as age was increasing an increase of ACS was observed to increase, this relational can be argued that in this era as a result of demographic change aging is a risk factor for many non-communicable diseases including ACS. This can be explained by the fact that atherosclerosis advances as the age of a person increases [18]. The disease was more prevalent in males $(78.5 \%)$ than females $(21.5 \%)$ with a ratio of 3.7 to 1 , as well as 55 percent in the older age group greater than 60 years old. A review study that was done for SSA documented also a higher ratio of male predominating results ranging between $1.3-6$ for males and 1 for female $[6,11]$. This result can be argued that males experience more to the modifiable behavioral risk factors such as smoking, alcohol use and others which lead mainly to non-communicable diseases. Eritrea as developing country urbanization is increasing; the highly urbanized area is zoba Maekel which is proximal to the ONRH-ICU, the only ICU highly equipped in terms of material and human resource. Eritrea is a country with two religions Christianity and Muslim and almost about 55 percent of the populations are Christian. Alcohol consumptions in the Christian community is very common mainly connected to ceremonials as traditional drink (Suwa, Meiss etc...). As it is indicated in a National Survey that was conducted in 2004 and 2010 alcohol consumption increased from 28.3 to 38.2 percent, showing a positive association with the increased in prevalence of DM from 2.3 to 4.7 percent that may lead also to ASC as a risk factor [16, 17]. Even though no record was found alcohol consumption either directly or indirectly as a risk factor it can supplement to the high prevalence of ACS.

The commonest complaint was chest pain $(85 \%)$. As it is reported by most patients a similar result was documented in previous studies in showing that as the most common presenting complaint in 93.1 percent of patients with ACS [19]. The average stay in the ICU until discharged or death was 11 days which is higher than a study in Switzerland that recorder an average stay of 9.5 days is increased [20]. This increased admission days is justified by less equipped and trained personnel's in the low income countries health care facility setting. This was proved by a study that was done by keller et al. (2012), a decrease of days of admission from 8 days to 6 days in NSTEMI patients and from 8 to 7 days in STEMI patients [21]. Majority of the patients were selfreferrals because people are becoming aware with their disease and know that there is a need of sophisticated equipment and highly trained personnel for the management of any cardiovascular disease. This hospital is also equipped with spirometers, Electro Cardio- graph (ECG), perfusers, others materials and trained medical staff that are required for the management of acute emergency diseases that include cardio-pulmonary diseases.

The presence or absence of smoking habit was found to be recorded only for 164 patient clinical cards and it was missed for 134. Despite the missed once it was as prevalent as 32.9 percent but overall prevalence for the whole study population was found to be 18.1 percent which is higher than that of the total population smoking habit in 2004 (8.7\%) and 2010 $(2.2 \%)[16,17]$. Smoking is one of the main risk factors for ACS with attributable risk together with dyslipidemia of 2 out of 3 Globally [8]. Hypertension and diabetes were found to be almost equally prevalent as risk factors represented as 36.7 and 30.9 percent. This study results have similarity with a study that was conducted in Africa that showed 42.3 and 23.6 percent for hypertension and diabetes in patients with ACS; which is lower than that of European that documented hypertension and diabetes to be prevalent as 56 and 21 percent $[9,22]$. Even though there are risk factors that should be studied in these patients but the data recordings were found to be weak in evaluating history of alcohol use, physical activity, nutritional habit, comorbidity with other infectious and non-infectious diseases and risk factors. A study that was conducted in 2004 and 2010 in Eritrea indicated that the prevalence of Alcohol consumption, Fruit and Vegetables consumption $<5$ servings / day and Physical inactivity ( $<600$ MET minutes/ week) as; 28.3, 97.6 and 42.1 in 2004, and 38.2, 97.5 and 19.7 percent in 2010 [16, 17]. The study results indicated a prevalence of 30.87 and 36.58 percent for Diabetes and Hypertension. Comorbidity among these three diseases was observed with significant association. A cross sectional study that was done in 2000, in Saudi Arabia documented a comorbidity of Diabetes and Hypertension with a prevalence of 44.9 and 27.6 percent in patients with ACS which is higher for diabetes and lower for hypertension than this study [23]. Out of the 298 patients with ACS 51 (17.1\%) were found to have both Diabetes and Hypertension, the study results indicated that a significant 
association between diabetes and hypertension at a $\mathrm{P}$ value $<$ 0.001 . Therefore, form the above studies we can argue that comorbidity of hypertension, diabetes and ACS is evident. And clinicians should be aware of these diseases. The study results also revealed a significant association between sex and, NSTEMI and STEMI at a P- value $=0.003$, but no any association was found among NSTEMI and STEMI, and age, smoking, cholesterol level, diabetes and hypertension

The study has limitations because it didn't include some modifiable risk factors such as Body Mass Index (BMI) and waist circumference which would have put light on the burden of obesity as a risk factor and other types of diagnostic and treatment modalities. But as the study is based on retrospective review of clinical cards it gives information as a base line study.

In conclusion, this study revealed that ACS is increasing in Eritrea as any other developed and developing countries is experiencing. ACS is fatal and its short-term outcome includes MI which is an immediate killer. Eritrea is facing this problem as a result of some modifiable behavioral risk factors such as; alcohol consumption and sedentary lifestyles of which are the great risk factors in developing CAD. The study also indicated that the association between sex and ACS which may be attributed to modifiable behavioral risk factors that are gender related. Therefore, the study recommends to Clinicians to pay attention for the management of patients with ACS through detailed questioning and record review, asking family history of premature CHD death, existence and duration of Diabetes and Hypertension by doing all diagnostic investigations and the use of specific and proper medication for getting a good outcome.

\section{Acknowledgements}

The research team is thankful to all staff at Orotta National Referral Hospital, and documentation and recording unit for their support in keeping the medical records of the patients and providing to the research team.

\section{Conflict of Interest Statement}

All the authors do not have any possible conflicts of interest.

\section{Nomenclature}

$\begin{array}{ll}\text { ACS } & \text { Acute Coronary Syndrome } \\ \text { BMI } & \text { Body Mass Index } \\ \text { CAD } & \text { Coronary Artery Disease } \\ \text { CHD } & \text { Coronary Heart Disease } \\ \text { CVD } & \text { Cardiovascular Disease } \\ \text { ECG } & \text { Electro Cardio- graph } \\ \text { HRRH- } & \text { Halibet Regional Referral Hospital Intensive } \\ \text { ICU } & \text { Care Unit } \\ \text { ICD } & \text { International Classification of Diseases } \\ \text { ICU } & \text { Intensive Care Unit }\end{array}$

$\begin{array}{ll}\text { IPMD } & \text { In-Patient Medical Department } \\ \text { MI } & \text { Myocardial Infarction } \\ \text { ONRH- } & \text { Orotta National Referral Hospital Intensive } \\ \text { ICU } & \text { Care Unit } \\ \text { SSA } & \text { Sub-Saharan African } \\ \text { WHO } & \text { World Health Organization }\end{array}$

\section{References}

[1] Roger, V. L., et al., Executive Summary: Heart Disease and Stroke Statistics--2011 Update: A Report From the American Heart Association. Circulation, 2011. 123(4): p. 459.

[2] Okrainec K, Banerjee DK, Eisenberg MJ. Coronary artery disease in the developing world. American heart journal. 2004 Jul 31; 148(1):7-15.

[3] Bitton A, Gaziano T. The Framingham Heart Study's impact on global risk assessment. Progress in cardiovascular diseases. 2010 Aug 31; 53(1):68-78.

[4] Ergin A, Muntner P, Sherwin R, He J. Secular trends in cardiovascular disease mortality, incidence, and case fatality rates in adults in the United States. The American journal of medicine. 2004 Aug 15; 117(4):219-27.

[5] Walker AR, Sareli P. Coronary heart disease: outlook for Africa. Journal of the Royal Society of Medicine. 1997 Jan; 90(1):23-7.

[6] Onen CL. Epidemiology of ischaemic heart disease in subSaharan Africa. Cardiovascular journal of Africa. 2013 Mar 1; 24(2):34-42.

[7] Hertz JT, Reardon JM, Rodrigues CG, de Andrade L, Limkakeng AT, Bloomfield GS, Lynch CA. Acute myocardial infarction in sub-Saharan Africa: the need for data. PloS one. 2014 May 9; 9(5):e96688.

[8] Yusuf S, Hawken S, Ôunpuu S, Dans T, Avezum A, Lanas F, McQueen M, Budaj A, Pais P, Varigos J, Lisheng L. Effect of potentially modifiable risk factors associated with myocardial infarction in 52 countries (the INTERHEART study): casecontrol study. The lancet. 2004 Sep 17; 364(9438):937-52.

[9] Steyn K, Sliwa K, Hawken S, Commerford P, Onen C, Damasceno A, Ounpuu S, Yusuf S. Risk factors associated with myocardial infarction in Africa. Circulation. 2005 Dec 6; 112(23):3554-61.

[10] Joseph VA. Frequency and Pattern of Acute Myocardial Infarction in the University of Benin Teaching Hospital, Nigeria. Nigerian Medical Practitioner. 2009; 55(6).

[11] Seyoum Y, Leake N. Clinical features of acute myocardial infarction: A report from Halibet Referral Hospital in Eritrea. Journal of the Eritrean Medical Association. 2006; 1(1).

[12] World Health Organization. Noncommunicable diseases country profiles 2014. 2014.

[13] Thygesen K, Alpert JS, Jaffe AS, Simoons ML, Chaitman BR, White HD, Writing Group on behalf of the Joint ESC/ACCF/AHA/WHF Task Force for the Universal Definition of Myocardial Infarction, Authors/Task Force Members Chairpersons, Thygesen K, Alpert JS, White HD. Third universal definition of myocardial infarction. European heart journal. 2012 Aug 24; 33(20):2551-67. 
[14] Mendis S, Thygesen K, Kuulasmaa K, Giampaoli S, Mähönen M, Ngu Blackett K, Lisheng L, Writing group on behalf of the participating experts of the WHO consultation for revision of WHO definition of myocardial infarction. World Health Organization definition of myocardial infarction: 2008-09 revision. International journal of epidemiology. 2010 Oct 4; 40(1):139-46.

[15] Shavadia J, Yonga G, Otieno H. A prospective review of acute coronary syndromes in an urban hospital in sub-Saharan Africa: cardiovascular topics. Cardiovascular journal of Africa. 2012 Jul 1; 23(6):318-21.

[16] MOH. Eritrea \& WHO. NATIONAL NON COMMUNICABLE DISEASE (NCD) RISK FACTOR BASELINE SURVEY (USING WHO STEP Swise APPROACH), 2004.

[17] MOH. Eritrea \& WHO. National STEPS Survey for Chronic Non-Communicable Diseases and their Risk Factors. 2012.

[18] Moran AE, Forouzanfar MH, Roth G, Mensah GA, Ezzati M, Flaxman A, Murray CJ, Naghavi M. The global burden of ischemic heart disease in 1990 and 2010: the Global Burden of Disease 2010 study. Circulation. 2014 Feb 26: CIRCULATIONAHA-113.
[19] Malik MA, Khan SA, Safdar S, Taseer IU. Chest Pain as a presenting complaint in patients with acute myocardial infarction (AMI). Pakistan journal of medical sciences. 2013 Apr; 29(2):565.

[20] Bramkamp M, Radovanovic D, Erne P, Szucs TD. Determinants of costs and the length of stay in acute coronary syndromes: a real life analysis of more than 10000 patients. Cardiovascular drugs and therapy. 2007 Oct 1; 21(5):389-98.

[21] Keller T, Tzikas S, Scheiba O, Krahn U, Post F, Arnolds S, Blankenberg S, Warnholtz A, Münzel T, Genth-Zotz S. The length of hospital stay in patients with acute coronary syndrome is reduced by establishing a chest pain unit. Herz. 2012 May; 37(3):301-7.

[22] Willich SN, Müller-Nordhorn J, Kulig M, Binting S, Gohlke $\mathrm{H}$, Hahmann H, Bestehorn K, Krobot K, Völler H. Cardiac risk factors, medication, and recurrent clinical events after acute coronary disease. A prospective cohort study. European Heart Journal. 2001 Feb 1; 22(4):307-13.

[23] Assiri AS. Knowledge about coronary artery disease among patients admitted to Aseer Central Hospital with acute coronary syndrome. West African journal of medicine. 2003; 22(4):314-7. 